
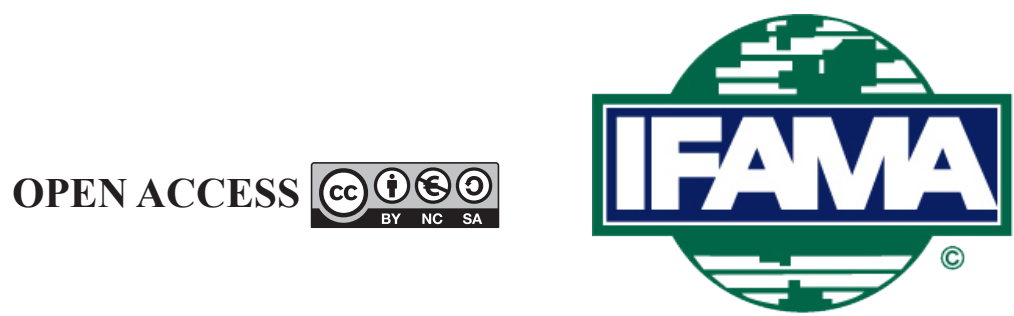

International Food and Agribusiness Management Review

Volume 22 Issue 4, 2019; DOI: 10.22434/IFAMR2018.0083

Received: 6 August 2018 / Accepted: 13 December 2018

\title{
Research on crop insurance and change in farmers' welfare: evidence from China's Inner Mongolia
}

\author{
RESEARCH ARTICLE \\ Lijuan Zhao ${ }^{\circledR a}$, Junhong Shi ${ }^{b}$, Xiaohong Kang ${ }^{\mathrm{c}}$ and Hua Hong ${ }^{\mathrm{c}}$ \\ ${ }^{a}$ Professor, ${ }^{c}$ Assistant professor, College of Finance, Inner Mongolia University \\ of Finance and Economics, Hohhot 010070, China P.R. \\ ${ }^{b}$ Professor, College of Economics, Inner Mongolia University of \\ Finance and Economics, Hohhot 010070, China P.R.
}

\begin{abstract}
Using Amartya Sen's capability approach and household survey data from Inner Mongolia, China, this paper constructs a welfare index in order to examine the impact of crop insurance on the welfare of farmers. Fuzzy comprehensive evaluation methods were used to measure changes in farmers' welfare before and after participating in crop insurance, and these were empirically tested to identify differences in the factors affecting farmers' welfare. It was found that after participating in crop insurance, the overall welfare level of farmers slightly increased. Many functional indicators improved, such as family economic status, working status, protective security, and psychological experience; however, the living environment and leisure time of farmers deteriorated after participation. From the perspective of conversion factors, variables such as the educational level of the head of household, the total number of members in a given household, the policy of crop insurance and regional economic development level all have a significant impact on the changes in farmers' welfare.
\end{abstract}

Keywords: crop insurance, welfare, fuzzy evaluation, capabilities, farmers JEL code: O12, Q12, Q14, Q18

\footnotetext{
(i)Corresponding author: zhaolijuannmg@126.com
} 


\section{Introduction}

In recent years, through the government's strong intervention and the use of financial subsidies, the scale of China's crop insurance industry has expanded rapidly. The crop insurance premiums have increased from 7.44 hundred million US\$ in 2007 to 5.99 billion US\$ in 2016, showing an average annual growth rate of $26.08 \%$ over the last 10 years. The business scale of crop insurance has become the second largest in the world after the United States. The rapid development of crop insurance has effectively compensated rural households for economic losses and quickly restored crop production after disasters. These economic benefits to rural households have also been maintained to some extent (Qiu and Zheng, 2016). At the same time, as an innovation in supporting agriculture policy, crop insurance has attracted great attention of the wider academic community and government. In recent years, China's central documents have continuously focused on crop insurance, emphasizing the need to increase crop insurance support and promote the healthy development of crop insurance, which fully reflects the important role of crop insurance in China's agricultural development. On the macro level, crop insurance is beneficial to the rural social security system. On the micro level, crop insurance helps micro-level farmers achieve their goals. In particular, insurance allows ordinary farmers to maximize their own success and security. Crop insurance and its subsidy policies are playing an increasingly important role in stabilizing farmers' income and promoting agricultural and rural economic development.

The topic of crop insurance has long been a focus of the academic community. In recent years, scholars both within China and internationally - have conducted extensive research on related issues. These studies can be divided into four categories. One is the study of supply failures in the crop insurance market, which mainly focuses on the lack of supply (Wright and Hewitt, 1994; Xia et al., 2015), the reasons for supply failures (Duncan and Myers, 2000; Zhang et al., 2013), and the measures for addressing supply failures in the crop insurance market (Goodwin and Smith, 2012; Xu et al., 2016). Another is a discussion of the effective demand for crop insurance. The general consensus among the in-depth studies of crop insurance is that, based on the empirical analysis that has been conducted (Cole et al., 2013; Hou et al., 2010; Liu et al., 2016), there are many factors that influence the level of effective demand. For example, Babcock (2011) found crop insurance subsidies could effectively increase farmers' enthusiasm for participating in crop insurance. Ghazanfar et al. (2015) believed that educational level and rural credit are the two most important factors. Therefore, raising the educational level and increasing rural credit can increase rural households' demand for crop insurance. Zhao and Chai (2012) pointed out that age demographics of the rural population, the farmers' educational level and behavioral choices, and insurance rates are also important reasons for the lack of effective demand for crop insurance. A third category is an analysis of the impact of crop insurance development on agricultural production. Many studies have focused on the impact of crop insurance on crop yields. Some have concluded that crop insurance promotes the growth of crop yields (Carter et al., 2016; Chen, 2004; Liang et al., 2008) while others have obtained the diametrically opposite result, finding that crop insurance has no significant effect on crop yields, and the effect of welfare did not achieve the theoretical analysis predictions (Goodwin et al., 2004; Huang, 2015; Zhang et al., 2006). The final category is an exploration of the relationship between crop insurance and farmers' income. Crop insurance affects the probability distribution of net agricultural income and with the stabilization of farmers' income as the key objectives of crop insurance (Kraft, 1996; Liang et al., 2008), scholars will naturally to pay close attention to this issue. The results of Torkamani's (2009) study show that crop insurance can effectively reduce farmers' aversion to agricultural risks and has a positive impact on the income distribution of rural households. Enjolras et al. (2012) pointed out that crop insurance could not only stabilize farmers' income but also reduce low-income volatility. In theory, according to neoclassical economics theory and the rational economic man hypothesis, people change their economic behavior in order to maximize their effectiveness for the sake of their families. The primary purpose of purchasing crop insurance is to ensure the wellbeing of the family. The issues of crop insurance and farmers' welfare have attracted the attention of scholars, many of whom have used Siamwalla and Valdes's consumer residual analysis methods or analyzed the welfare effects of crop insurance from either a macro or a theoretical perspective (Feng, 2004; Li, 1996; Mishra, 1996). However, Zhang and Shi (2007) found that this method has some defects. Therefore, they used the utility maximization method to analyze the relationship between crop insurance and welfare and, to a certain extent, improved the original 
theoretical system. In recent years, some scholars have also analyzed the welfare effects of crop insurance from the perspective of micro-farmers. For example, Nie et al. (2013) created a characteristic index of farm households to evaluate the welfare significance and economic performance of policy-based crop insurance. However, compared with the fuzzy comprehensive evaluation method, this method has problems such as insufficient comprehensiveness and refinement of evaluation indicators.

From the above analysis, we can see that the issue of crop insurance has received extensive attention, with substantial relevant research results. However, few studies have incorporated the theory of crop insurance and farmers' family welfare into an overall research framework. Crop insurance is an important tool for rural risk management and will induce changes in the production behavior of rural households. There are significant influences on employment, land circulation, and labor input behaviors that directly affect farmers' welfare. However, current relevant empirical research is very scarce, and there is still a lack of quantitative analysis on whether crop insurance increases the welfare of rural households. There is literature that supports welfare brought about by crop insurance, either through macro-perspective analysis of social and national welfare or from micro-perspective analysis of family welfare with a few characteristic indicators. However, there is lack of follow-up measurement of the multi-dimensional welfare level and welfare changes of farmers' families before and after participating in crop insurance. Therefore, in the framework of Amartya Sen's capability approach, this paper attempts to measure and evaluate the welfare changes of farmers in Inner Mongolia, China, before and after participating in crop insurance, through a fuzzy comprehensive evaluation method. This paper will empirically examine the factors influencing changes in the farmers' family welfare from a micro perspective, with the aim of providing reference for improving crop insurance policies and the welfare of farmers.

\section{Composition of farmers' welfare}

\subsection{Functional indicators that constitute the welfare of farmers}

In the 1980s and 1990s, the economist Amartya Sen proposed the theory of capability. The core idea of this theory is to use the 'capability of individuals to realize valuable activities' to evaluate the quality of life (Sen, 1992, 1993). In essence, this theory redefined the concept of welfare. The so-called 'capability' refers to 'the ability to enjoy the kind of life that people have reason to value' (Sen, 1993). In simple terms, it refers to a combination of possible functional indicators that one might achieve. He examined six functional indicators: income levels, living conditions, health conditions, education and knowledge, social interaction, and psychological conditions. These indicators are expressed through five instrumental freedoms: political freedom, economic conditions, social opportunities, guaranteed transparency, and protection. However, the five instrumental freedoms and six functional indicators of Sen are not the full contents of the capability. After researching, we can find many kinds of valuable functional indicators, and some of these instrumental freedoms are not listed in Sen's theory. The advantage of Sen's method is that it considers more of the benefits outside of utility and emphasizes that the maximization of welfare should be the goal, including not only an increase in income but also rights, equality, and guarantees of freedom. Sen's capability approach only provides a general analysis framework for welfare issues. In our research, we need to determine different indicators based on our own research objectives and research background, focusing especially on particular variables. We know that the welfare of farmers covers a wide range of topics. We assess the main functional indicators of farmers' welfare that change before and after participating in crop insurance, that is, based on Sen's theory of available capabilities, combining past research and implementation of crop insurance in China, we selected six functional indicators - the family's economic status, working status, protective security, environment, leisure time, and psychological experience to examine the changes in farmers' welfare before and after participating in crop insurance. The following is a detailed discussion of each indicator and related hypothetical statements for the relationships between crop insurance and each of the welfare indicators.

1. Family's economic status. In traditional welfare economics, income is generally used to represent the level of welfare. Although this approach is unreasonable, there is no doubt that economic conditions are certainly the most important element in the measurement of welfare effects. In China, decentralizing 
the agricultural risks faced by farmers, safeguarding and raising their income, and ultimately improving the welfare of farmers are the most basic aims of crop insurance. Specific indicators that measure the family's economic status include agricultural income, non-agricultural income, net income, and consumer spending. Before getting the final result, we make the hypothesis that crop insurance may increase farmers' agricultural income, net income and consumption expenditure, but reduce non-agricultural income. The possible reason is that crop insurance reduces the risk of agricultural production, allowing farmers to be less cautious and change planting structures, expand planting area, increase productive investment and agricultural production efficiency, all of which will firstly affect the agricultural income of farmers, which in turn stimulates the consumption of farmers, and thus their net income changes. In addition, with the guarantee of crop insurance, the time for farmers to invest in agriculture may increase, which will inevitably reduce non-agricultural working hours, and non-agricultural income will decrease.

2. Work status. The state of work is directly related to the welfare of farmers. From an instrumental point of view, good working conditions will have a direct impact on health and mental wellbeing. In this paper, farmers' work intensity, employment opportunities, and job satisfaction are used to measure the dimensions of the working status. Work intensity is measured by working hours, which is the time spent on farming and other employment. If the implementation of crop insurance allows farmers to increase their production scale with confidence, then their working hours will inevitably increase along with possible economic benefits. However, the cost of increased capacity is a reduction of leisure time, resulting in a decline in non-economic benefits. However, if the scale of employment also increases, the number of employed workers will increase, and the work intensity will inevitably decline. Although some income is lost through the hiring of more workers, the leisure time and the non-economic benefits will increase. Finally, we will evaluate farmers' degree of job satisfaction. Job satisfaction not only affects farmers' enthusiasm and disposition, but also influences their income. Therefore, the level of job satisfaction will undoubtedly impact the family's welfare.

3. Protective security. Sen emphasized that protective security is a social safety net that can provide support for vulnerable groups. This paper selects three important indicators to measure the protection status of farmers - the area of cultivated land, the quality of the cultivated land, and the strategy to deal with agricultural risks. For peasants, arable land is the most important resource with social security functions, as it is the primary source of their livelihood and employment opportunities. Here we assume that after participating in crop insurance, farmers no longer worry about the high risks faced by the planting industry, which makes them dare to expand the scale of planting, rent more cultivated land from others, and the cultivated land area will inevitably be enlarged. In addition, farmers may invest more time and energy on cultivated land after purchasing crop insurance, and the quality of farmland will be improved. At the same time, after purchasing crop insurance, it has enriched farmers' strategies to deal with agricultural risks, which will inevitably increase the ability of farmers to withstand natural disasters and other risks.

4. Environment. With the development of the economy and society, the lives and environment of farmers are also an important part of their family's welfare. After participating in crop insurance, the living environment of peasant may undergo certain changes. Therefore, when examining the relationship between crop insurance and welfare, environmental factors should be considered. These factors include the amount of chemicals such as fertilizers and pesticides that used in the agricultural production process, because the increase in the input of these chemicals will in turn destroy the ecological environment of the countryside, as well as the attitudes of farmers in regard to their effect on the environment. Here we assume that the crop insurance will increase the use of fertilizers, pesticides, and mulches. The more chemicals used, the greater the potential for environmental damage in rural areas, and the farmers' subjective evaluation of air quality will also be reduced.

5. Leisure time. In order to obtain a greater sense of wellbeing, people require a certain amount of leisure time to enrich their daily lives, thereby enhancing their non-economic benefits. In economic theory, both income and leisure are included in the utility function. Only when the two are optimized in a balanced way can we maximize utility and ensure the optimization of welfare. Therefore, we linked family members' leisure time with family welfare and selected changes in the amount of leisure time 
to measure leisure activity. We make a hypothesis that after participating in crop insurance, the scale of production and labor intensity will both increase while farmers' leisure time may decrease, and their overall welfare level will be affected.

6. Psychological experience. Subjective emotions, such as happiness and satisfaction, are considered to be indispensable components of welfare and are important factors in the pursuit of higher levels of welfare. Therefore, this study also considers peasants' emotional wellbeing before and after participation in crop insurance in order to examine the impact of the above-mentioned functional indicators on farmers' welfare. After participating in crop insurance, the farmers' sense of security, feelings of life pressures, and quality of life will likely change, affecting their available capabilities, which will affect the attainment of higher welfare. Therefore, psychological indicators such as psychological burden, sense of security, and happiness were used to measure the psychological function of farmers.

\subsection{Conversion factors in farmers' welfare}

In the process of transferring goods to welfare, the degree of conversion and conversion efficiency will vary due to differences in individual, social, and environmental factors. Sen summarized these differences into five aspects: individual differences, environmental diversity, heterogeneity of the social environment, differences in interpersonal relationships, and distribution within the family. These conversion factors do not directly generate benefits but have an inherit impact on further generations and the smooth transition of welfare. When studying factors that affect farmers' welfare before and after participating in crop insurance, based on existing research and the research needs, the heterogeneity factors that cause changes in the welfare of farmers are divided into three basic categories: basic family characteristics, crop insurance policies, and regional economic development levels. Among them, the basic characteristics of family variables include the gender, age, and education of the head of the household and the total number of household members. Farmers' willingness to participate in crop insurance and satisfaction with it are two indicators that represent the variable of crop insurance policy. The economic development level of different regions allows people in different social environments and backgrounds access to different opportunities. Therefore, the per capita GDP was the fourth variable chosen to represent the level of economic development in different regions. In general, the higher the economic development of the area in which the farmers are located, the more opportunities they will have, and therefore, the higher the level of family welfare.

\section{Research methods and data sources}

\subsection{Research methods}

\section{- Fuzzy comprehensive evaluation method of farmers'welfare}

Welfare has obvious ambiguity and is a relatively broad concept, making it difficult to define accurately, and maintains its ambiguity even if it is to accurately describe the welfare. In addition, when assessing the welfare of rural households before and after participating in crop insurance, some of the selected indicators, such as job satisfaction, perception of air quality, and security, are subjective and potentially ambiguous. Fuzzy mathematics provides an idea for dealing with this type of problem that cannot be clearly defined. Sen also believes that fuzzy mathematics is suitable for the evaluation of feasible methods. Therefore, the fuzzy comprehensive mathematics method was chosen to objectively evaluate the welfare changes of farmers. Fuzzy mathematics has been widely used in different research fields and has been used in recent years to study poverty, fairness, and welfare issues (Cheli and Lemmi, 1995; Gao et al., 2007; Jia and Wang, 2014; Martinetti, 2000). Due to the limited availability of data, some virtual qualitative variables before farmers' participation in crop insurance were not well documented. Therefore, this study makes the following assumptions: the welfare status of farmers after insurance participation is taken as the reference point for welfare status before participation. The peasant's family welfare will be set to a fuzzy status of 0.500 before they are enrolled in insurance and the welfare of the farmers after participation will be calculated and compared 
in reference to this starting point. In the fuzzy comprehensive evaluation method to measure the changes of farmers' welfare level before and after participating in agricultural insurance, it mainly includes three steps.

First, setting of fuzzy function of the welfare. The level of peasant welfare is expressed as fuzzy set $X$. The six items, including household economic conditions, working conditions, protective security, environment, leisure, and psychological experience in Table 2 constitute a subset $W$ of $X$, and then the welfare function of the $n$th household can be expressed as $W^{n}=\{x, \mu(x)\}$, where $x \in X, \mu_{w}(x)$ is the degree of membership of $x$ to $W, \mu_{w}(x) \in[0,1]$. In general, the degree of membership is 1 when the welfare status is in an excellent state, 0 when the welfare status is in a poor state, and 0.5 when the welfare status is the most ambiguous.

Second, setting of index variable and membership function. In practical scientific research, determining the membership function $\mu_{w}(x)$ is the primary task for solving the ambiguity problem. The relationship between the independent and dependent variables as well as the indicator type are the two most important factors in determining the membership function. In general, we classify indicator variables into three types: Virtual Dichotomy Variable (identified by the letter D), Virtual Qualitative Variable (identified by the letter Q), and Continuous Variable (identified by the letter C), see Table 1 for descriptions of variable assignments and explanations. Let $x_{i}$ be the $i$-th functional subset of the farmer's welfare, which is determined by the primary indicator $x_{i j}$. The primary indicator set for the farmer's welfare is $x=\left[x_{11} \ldots, x_{i j} \ldots\right]$. The membership functions used for different types of variables are also different.

Last, the sum of primary indicators. After calculating the degree of membership of the primary indicator, it is necessary to add the membership to a comprehensive indicator, which requires the weight of the indicator. According to existing studies, this paper uses the formula proposed by Chelia and Lemmi (1995) to determine the weight, which is the most commonly used method to determine weights when using fuzzy comprehensive evaluation of welfare:

$$
\omega_{i j}=\operatorname{Ln}\left[1 / \overline{\mu\left(x_{i j}\right)}\right]
$$

In Equation 1, $\overline{\mu\left(x_{i j}\right)}=\frac{1}{n} \sum_{p}^{n} \mu\left(x_{i j}\right)^{(p)}$ represents the mean value of the $j$-th indicator in the $i$-th functional subset of $n$ farmers. The degree of membership of each subset of functions is based on the degree of subordination and weighting of the primary indicators and can be calculated based on the following summation formula proposed by Cerioli et al. (1990):

$$
\mu\left(x_{i}\right)=\sum_{j=1}^{k} \overline{\mu\left(x_{i j}\right)} * \omega_{i j} / \sum_{j=1}^{k} \omega_{i j}
$$

In Equation 2, $k$ denotes that $k$ primary indicators are included in the $i$-th functional indicators subset. Therefore, the formula for the total membership degree of farmers' family welfare measures can be expressed by the following equation:

$$
W=\sum_{i=1}^{h} \mu\left(x_{i}\right) * \omega_{i} / \sum_{i=1}^{h} \omega_{i}
$$

In Equation 3, the weight of each functional activity is $\omega_{\mathrm{i}}=\operatorname{Ln}\left[1 / \mu\left(x_{i}\right)\right]$, where $h$ represents the number of functional indicators.

\section{- Model construction of factors affecting changes in the farmers'welfare}

In this paper, a multivariate regression model was constructed to quantitatively analyze the main factors affecting farmers' welfare changes before and after participating in crop insurance. The specific model we constructed is as follows:

$$
Y=\beta_{0}+\beta_{1} F+\beta_{2} I+\beta_{3} R+\mu
$$


In Equation 4, $Y$ is the explanatory variable, which represents the changed value of farmers' welfare levels, expressed as the difference between the welfare levels of individual farmers after participating in crop insurance minus the welfare level before participation in crop insurance. $F, I$ and $R$ represent the family's basic characteristics, crop insurance policies, and regional economic development level in the explanatory variables respectively, and $\mu$ is the random perturbation term.

\subsection{Data sources and sample characteristics}

The data used in this paper originated from the investigation of farmers participating in crop insurance in 5 cities in Inner Mongolia Autonomous Region, 8 townships in 8 counties, and 20 villages between July and August 2017. The reason why Inner Mongolia was selected as the research area of this paper was because China started the pilot project of policy crop insurance in 2007, and Inner Mongolia was one of the seven earliest pilot provinces. Secondly, the authors of the study have been working and living in Inner Mongolia for many years and are very familiar with it. They conducted a long-term follow-up study of the area and have obtained a series of relatively detailed survey data. During the survey, a combination of typical and random sampling methods were used, that is, the study area was selected by typical sampling, 5 typical cities which including 8 counties, 13 towns and 20 villages with a large agricultural output value were selected from the total 14 cities in Inner Mongolia; and the sample farmers were selected by random sampling, just because this method can ensure that the distribution characteristics of the sample units extracted are basically consistent with the distribution characteristics of the overall unit, and are fully representative. A total of 520 questionnaires were distributed to farmers in the sample areas, and 512 valid questionnaires were collected. Among them, 151 were collected in Chifeng, 88 in Xing'an, 81 in Baotou, 142 in Ordos, and 50 in Bayannur. These 5 cities were selected as the study areas because they represent the eastern, central, and western regions of Inner Mongolia, China. Chifeng and Xing'an are located in the eastern region, Baotou is located in the central region, and Erdos and Bayannur are located in the western region of Inner Mongolia. In 2016, GDP per capita of these regions was US\$ 6,456.23, US\$4,690.88, US\$1,9542.97, US\$ 30,960.47, and US\$ 7,827.47, respectively. The per capita GDP of Xing'an was the lowest among the 14 cities of the Inner Mongolia Autonomous Region, and the per capita GDP of Ordos was the highest. Therefore, the selected regions can also represent the high, medium, and low-level economic regions in Inner Mongolia.

This study firstly carried out a simple statistical analysis of the basic characteristics of household heads participating in crop insurance families. The survey results show that the head of the households were predominantly male (87.11\%). The most prominent age range was $40-60$ years old, accounting for $66.99 \%$ of those surveyed. Those under 40 years accounted for $26.56 \%$ while farmers over the age of 60 represented only $6.45 \%$ of the total number surveyed. This shows that most people in the surveyed areas engaging in agricultural production were under the age of 60 . In terms of education, $35.94 \%$ of those surveyed had a high school education or above, and $35.16 \%$ of the households had a junior high school education, which is consistent with the actual demographics in the Inner Mongolia Autonomous Region. In order to better understand the situation of administrative villages and the implementation of related policies during the investigation process, it is necessary to ask the relevant village cadres. However, in order to avoid political factors affecting the survey results, we only selected $20.90 \%$ of the village cadres. Among the rural households, $67.97 \%$ of households mainly engaged in farming, and such distribution effectively increased the reliability of the data.

\section{Empirical analysis of farmer welfare changes before and after participation in crop insurance}

\subsection{Indicator definition and descriptive statistics}

Drawing from the theoretical analysis and field survey data, the definition of the primary indicators for the evaluation of farmer welfare and the descriptive statistical analysis are as shown in Table 1. 
Table 1. Definition of primary indicators and descriptive statistical analysis results.

\begin{tabular}{|c|c|c|c|c|}
\hline $\begin{array}{l}\text { Functional indicators and } \\
\text { corresponding primary } \\
\text { indicators }\end{array}$ & Types $^{1}$ & Definitions and assignments & $\begin{array}{l}\text { Before } \\
\text { insurance }\end{array}$ & $\begin{array}{l}\text { After } \\
\text { insurance }\end{array}$ \\
\hline \multicolumn{5}{|l|}{ Family economic status } \\
\hline Agricultural income & $\mathrm{C}$ & $\begin{array}{l}\text { Annual household per capita agricultural net } \\
\text { income (US\$) }\end{array}$ & $\begin{array}{c}892.29 \\
(584.91)\end{array}$ & $\begin{array}{r}1,243.51 \\
(708.05)\end{array}$ \\
\hline Non-agricultural income & $\mathrm{C}$ & $\begin{array}{l}\text { Annual non-agricultural income per family } \\
\text { (US\$) }\end{array}$ & $\begin{array}{c}111.03 \\
(654.74)\end{array}$ & $\begin{array}{c}939.93 \\
(704.07)\end{array}$ \\
\hline Net income & $\mathrm{C}$ & $\begin{array}{l}\text { Annual per capita net income of family } \\
\text { (US\$) }\end{array}$ & $\begin{array}{r}1,454.77 \\
(659.71)\end{array}$ & $\begin{array}{r}1,631.03 \\
(640.90)\end{array}$ \\
\hline Expenditures & $\mathrm{C}$ & $\begin{array}{l}\text { Annual household per capita consumption } \\
\text { expenditure (US\$) }\end{array}$ & $\begin{array}{c}490.30 \\
(245.54)\end{array}$ & $\begin{array}{c}546.48 \\
(276.69)\end{array}$ \\
\hline \multicolumn{5}{|l|}{ Working status } \\
\hline Intensity of work & $\mathrm{C}$ & Annual family working time (days) & $\begin{array}{c}336.12 \\
(107.57)\end{array}$ & $\begin{array}{c}343.81 \\
(115.11)\end{array}$ \\
\hline Employment of labor & $\mathrm{D}$ & $0=$ no, $1=$ yes & $\begin{array}{c}0.40 \\
(0.49)\end{array}$ & $\begin{array}{c}0.41 \\
(0.49)\end{array}$ \\
\hline Job satisfaction & Q & $\begin{array}{l}1=\text { not satisfied, } 2=\text { less satisfied, } 3= \\
\text { average, } 4=\text { more satisfied, } 5=\text { satisfied }\end{array}$ & $\begin{array}{c}3.00 \\
(0.00) \\
\end{array}$ & $\begin{array}{c}3.63 \\
(1.17) \\
\end{array}$ \\
\hline \multicolumn{5}{|l|}{ Protective security } \\
\hline Cultivated land area & $\mathrm{C}$ & Annual per capita farm land area (ha) & $\begin{array}{c}0.64 \\
(0.42)\end{array}$ & $\begin{array}{c}0.76 \\
(0.54)\end{array}$ \\
\hline Cultivated land quality & Q & $1=$ worse, $2=$ no change, $3=$ better & $\begin{array}{c}2.00 \\
(0.00)\end{array}$ & $\begin{array}{c}2.47 \\
(0.68)\end{array}$ \\
\hline $\begin{array}{l}\text { Strategies for agricultural } \\
\text { risks }\end{array}$ & Q & $\begin{array}{l}\text { Family responds to agricultural risks } \\
\text { strategy adopted (species) }\end{array}$ & $\begin{array}{c}1.56 \\
(0.77) \\
\end{array}$ & $\begin{array}{c}2.31 \\
(0.80) \\
\end{array}$ \\
\hline \multicolumn{5}{|l|}{ Environment } \\
\hline $\begin{array}{l}\text { Fertilizer application } \\
\text { amount }\end{array}$ & $\mathrm{C}$ & $\begin{array}{l}\text { Average fertilizer application expenditure } \\
\text { per ha (US\$) }\end{array}$ & $\begin{array}{c}343.95 \\
(200.67)\end{array}$ & $\begin{array}{c}372.86 \\
(177.21)\end{array}$ \\
\hline $\begin{array}{l}\text { Subjective perception of air } \\
\text { quality }\end{array}$ & Q & $\begin{array}{l}1=\text { significantly degraded } 2=\text { degraded } 3= \\
\text { no change } 4=\text { better } 5=\text { obviously better }\end{array}$ & $\begin{array}{c}3.00 \\
(0.00)\end{array}$ & $\begin{array}{r}1.87 \\
(0.61) \\
\end{array}$ \\
\hline \multicolumn{5}{|l|}{ Leisure } \\
\hline Break time & Q & $\begin{array}{l}1=\text { obviously less, } 2=\text { less, } 3=\text { no change } \\
4=\text { more, } 5=\text { significantly more }\end{array}$ & $\begin{array}{c}3.00 \\
(0.00) \\
\end{array}$ & $\begin{array}{c}2.95 \\
(0.99)\end{array}$ \\
\hline \multicolumn{5}{|l|}{ Psychological experience } \\
\hline Mental burden & Q & $\begin{array}{l}1=\text { significantly increased, } 2=\text { improved, } \\
3=\text { no change, } 4=\text { lower, } 5=\text { significantly } \\
\text { lower }\end{array}$ & $\begin{array}{c}3.00 \\
(0.00)\end{array}$ & $\begin{array}{c}3.76 \\
(1.20)\end{array}$ \\
\hline Sense of security & Q & $\begin{array}{l}1=\text { significantly lower, } 2=\text { lower, } 3=\text { no } \\
\text { change, } 4=\text { higher, } 5=\text { significantly higher }\end{array}$ & $\begin{array}{c}3.00 \\
(0.00)\end{array}$ & $\begin{array}{c}4.04 \\
(0.86)\end{array}$ \\
\hline Sense of happiness & Q & $\begin{array}{l}1=\text { significantly lower, } 2=\text { lower, } 3=\text { no } \\
\text { change, } 4=\text { higher, } 5=\text { significantly higher }\end{array}$ & $\begin{array}{c}3.00 \\
(0.00)\end{array}$ & $\begin{array}{c}4.33 \\
(0.88)\end{array}$ \\
\hline
\end{tabular}

\subsection{Analysis of changes in welfare indices of farmers before and after crop insurance participation}

It can be seen from Table 2 that those surveyed increased their welfare after participating in crop insurance, but the increase was not significant. The fuzzy evaluation value of farmers' welfare increased from 0.466 to 0.500 , an increase of $7.30 \%$. This reflects that crop insurance has a role in promoting the overall welfare of 
Table 2. Results of fuzzy evaluation of farmers' welfare before and after participating in crop insurance.

\begin{tabular}{|c|c|c|c|c|c|c|}
\hline \multirow{2}{*}{$\begin{array}{l}\text { Functional indicators and } \\
\text { sub-indicators that should be } \\
\text { obtained }\end{array}$} & \multirow{2}{*}{$\begin{array}{l}\text { Variable } \\
\text { type }{ }^{1}\end{array}$} & \multicolumn{2}{|c|}{ Welfare Membership } & \multicolumn{2}{|l|}{ Weights } & \multirow{2}{*}{$\begin{array}{l}\text { Welfare } \\
\text { changes }\end{array}$} \\
\hline & & $\begin{array}{l}\text { Before } \\
\text { insurance }\end{array}$ & $\begin{array}{l}\text { After } \\
\text { insurance }\end{array}$ & $\begin{array}{l}\text { Before } \\
\text { insurance }\end{array}$ & $\begin{array}{l}\text { After } \\
\text { insurance }\end{array}$ & \\
\hline Family economic status & - & 0.355 & 0.373 & 1.036 & 0.986 & 0.018 \\
\hline Agricultural income & $\mathrm{C}$ & 0.345 & 0.396 & 1.064 & 0.926 & 0.051 \\
\hline Non-agricultural income & $\mathrm{C}$ & 0.351 & 0.328 & 1.047 & 1.115 & -0.023 \\
\hline Net income & $\mathrm{C}$ & 0.440 & 0.498 & 0.821 & 0.697 & 0.058 \\
\hline Expenditures & $\mathrm{C}$ & 0.311 & 0.324 & 1.168 & 1.127 & 0.013 \\
\hline Working status & - & 0.470 & 0.501 & 0.755 & 0.691 & 0.031 \\
\hline Intensity of work & $\mathrm{C}$ & 0.537 & 0.523 & 0.622 & 0.648 & -0.014 \\
\hline Employment of labor & $\mathrm{D}$ & 0.402 & 0.412 & 0.911 & 0.887 & 0.010 \\
\hline Job satisfaction & Q & 0.500 & 0.656 & 0.693 & 0.422 & 0.156 \\
\hline Protective security & - & 0.492 & 0.608 & 0.709 & 0.498 & 0.116 \\
\hline Cultivated land area & $\mathrm{C}$ & 0.460 & 0.518 & 0.777 & 0.658 & 0.058 \\
\hline Cultivated land quality & $\mathrm{Q}$ & 0.500 & 0.733 & 0.693 & 0.311 & 0.233 \\
\hline Strategies for agricultural risks & $\mathrm{Q}$ & 0.521 & 0.657 & 0.652 & 0.420 & 0.136 \\
\hline Environment & - & 0.542 & 0.484 & 0.612 & 0.726 & -0.058 \\
\hline Fertilizer application amount & $\mathrm{C}$ & 0.599 & 0.557 & 0.512 & 0.585 & -0.042 \\
\hline $\begin{array}{l}\text { Subjective perception of air } \\
\text { quality }\end{array}$ & Q & 0.500 & 0.434 & 0.693 & 0.835 & -0.066 \\
\hline Leisure & - & 0.500 & 0.486 & 0.693 & 0.722 & -0.014 \\
\hline Break time & Q & 0.500 & 0.486 & 0.693 & 0.722 & -0.014 \\
\hline Psychological experience & - & 0.500 & 0.747 & 0.693 & 0.292 & 0.247 \\
\hline Mental burden & Q & 0.500 & 0.694 & 0.693 & 0.365 & 0.194 \\
\hline Sense of security & $\mathrm{Q}$ & 0.500 & 0.832 & 0.693 & 0.184 & 0.332 \\
\hline Sense of happiness & Q & 0.500 & 0.760 & 0.693 & 0.274 & 0.260 \\
\hline Total fuzzy index & - & 0.466 & 0.500 & - & - & 0.034 \\
\hline
\end{tabular}

${ }^{1} \mathrm{D}=$ virtual dichotomy variable; $\mathrm{Q}=$ virtual qualitative variable; $\mathrm{C}=$ continuous variable.

farmers, but it is not significant. From the standpoint of individual welfare indicators, crop insurance has a great impact on the individual functional activities of farmers' welfare. Some indicators of functional indicators improved, such as family economic status, working status, protective security, and psychological experience, especially the two welfare functions of security and psychological experience improved significantly, the comprehensive evaluation value is 0.116 and 0.247 higher than the state of welfare before participation in crop insurance. However, some indicators of functional indicators deteriorated, such as the environment and leisure functions. The following is an analysis of the changes in each specific indicator.

\section{- Family economic status}

Overall, the economic status of the surveyed farmers increased slightly after participating in the crop insurance. There was an increase from 0.355 before participation to 0.373 after participation, but the changes in the functional indicators of the household economy varied. The indicators of agricultural income, net income, and consumer spending increased; however, non-agricultural income decreased. The reason for this is that the implementation of crop insurance policy results in changes in the planting structure and area. With crop insurance as a guarantee, farmers expanded their planting scale, primarily by renting other people's cultivated land, thereby increasing the total cultivated area. According to the survey data, $30.86 \%$ of rural households expanded their planting scale after purchasing crop insurance, which in turn promoted the farmers' income. At the same time, after participating in crop insurance, farmers were able to adopt more effective and challenging production tools. Another $35.35 \%$ of the farmers changed the planting structure and increased the 
planting areas for economic crops. On the whole, the increase in agricultural income optimized net income. Without crop insurance, farmers cannot be effectively motivated to cultivate more land and high-risk crops. Many farmers do not want to rely on agricultural land with high natural risks. In order to maintain their welfare level, they have to enter non-agricultural industries and increase their non-agricultural income. The results show that the non-agricultural income index, as a percentage of household income before insurance participation, was 0.351 but decreased to 0.328 after participation in crop insurance.

In addition, when rural households participate in crop insurance, their sense of future security increases, which in turn stimulates household consumption. Conversely, when security and certainty of the future declines, consumption also declines at the same time, especially in periods of high agricultural production risk. Insurance plays an important role in stabilizing agricultural production and increasing farmers' income. This inevitably increases farmers' consumption. Through the above four indicators, the economic household conditions clearly reflected a slight improvement after participating in crop insurance.

\section{- Working status}

The surveyed farmers' degree of subordination of the work status rose from 0.470 before participation to 0.501 after participation. The increase was not significant, and the welfare status was neither good nor bad. Sub-indicators showed that after the purchase of crop insurance, farmers hired more laborers, but the intensity of work did not decrease. This may be due to the expansion of the scale of planting and increased working hours and effort. Although the intensity of work remained the same, the farmers' satisfaction with their work was significantly higher. The degree of membership increased from 0.500 to 0.612 after participation in crop insurance, and family welfare improved, rising above the midpoint of 0.500 . Although they had less leisure time, perhaps the best explanation for the improvement of farmers' satisfaction would be that the higher income stimulated their enthusiasm and enjoyment of their work.

\section{- Protective security}

Compared with before the implementation of the crop insurance policy, the protection function of farmers was greatly improved, the degree of membership welfare increased from 0.492 to 0.608 . The subordinate values of the three indicators of area, cultivated land quality, and response to agricultural risk strategies all rose above 0.500 . Among them, the quality of cultivated land improved the most, with the degree rising from 0.500 to 0.733 after participation. Relatively speaking, crop insurance made a significant contribution to the improvement of cultivated land quality. Crop insurance objectively stimulated the expansion of land cultivation with guaranteed functions. The area of cultivated land also rose from 0.460 to 0.518 , indicating that crop insurance may lead to an increase in the cultivated area of the insured crops, in particular, as government subsidies and crop insurance coverage continue to increase, farmers' willingness to expand the cultivated area is even stronger. The welfare of farmers in responding to agricultural risk strategies is also relatively good. After the insurance coverage, the index of welfare indicators rose from 0.521 to 0.657 after insurance participation, demonstrating that the crop insurance made farmers' more resistant to risks. Overall, after participating in crop insurance, the status of farmers' protective security function improved.

\section{- Environment}

Among the six functions that constitute the welfare of farmers, the largest decline was in the environmental function, which was reduced from 0.542 before participation to 0.484 after participation, representing a decrease of $25.68 \%$. The crop insurance policies hindered the improvement of rural air quality to a certain extent. One reason is that the amount of chemical fertilizers used increased, resulting in a decreased quality of environmental conditions. The decision to purchase crop insurance promoted the use of fertilizers in agricultural production. The main reasons were a result of increased land cultivation and the improved confidence in agricultural production, which exacerbated the increase in chemical fertilizer usage, leading to agricultural non-point source pollution. From the perspective of the farmers, the air quality in rural areas 
was reduced compared with the quality before participation in insurance, with nearly a third of the surveyed farmers reporting a decline in air quality. Of course, the deterioration of air quality is also related to increased urbanization, the development of secondary and tertiary industries in rural areas, and the bad habits of rural people. Thus, it can be seen that after participating in crop insurance, the environmental functions of farmers have been damaged to a certain extent.

\section{- Leisure}

In this study, the rest time of farmers was selected to measure the change in leisure before and after their participation in insurance. The leisure time was reduced from the ambiguous state of 0.500 before participating to 0.486 afterward. This demonstrates that the rest time of the peasants decreased and labor intensity increased, which also confirms the analysis in the previous section. After participating in crop insurance, the economic welfare of rural households increased, but it damaged their non-economic benefits. It is gratifying that the increase in economic welfare is greater than the decline in non-economic benefits.

\section{- Psychological experience}

From the overall sample, the psychological experience index value and the value of its three sub-indicators are all above 0.6. Among the six functions that constitute the welfare of farmers, the largest increase was seen in the psychological experience function, which rose from 0.500 to 0.747 after participation in the insurance. This represents an increase of $49.40 \%$, indicating that participating in crop insurance plays a very important role in the psychological function of farmers and enhances their psychological wellbeing. Of the three sub-indicators, sense of security increased the most, and the degree of membership rose from 0.500 before participation to 0.832 . Crop insurance gave farmers more ways to effectively deal with agricultural risks, weakening the risks they faced in agricultural production and reducing the uncertainty of rural residents. Crop insurance could reduce the farmers' psychological burden, effectively eliminate their concerns, make them more confident about the future of agricultural production and their lives, and played an in important role in income expectations, leading to an increase in security and happiness.

\subsection{Analysis of the influence of transformation factors on farmers' welfare before and after participation in crop insurance}

In order to further study the influencing factors of the difference in household welfare before and after insurance participation, we use STATA13.0 software and the ordinary least squares (OLS) method to estimate the multiple regression model constructed above; the regression results obtained are shown in Table 3.

Table 3. Ordinary least squares estimation results of influencing factors of farmers' welfare changes before and after participating in crop insurance.

\begin{tabular}{llllll}
\hline Variable name & Coefficient $^{1}$ & $\boldsymbol{P}$-value & Variable name & Coefficient $^{\mathbf{1}}$ & $\boldsymbol{P}$-value \\
\hline Family basic features & & \multicolumn{5}{c}{ Crop insurance policy } \\
\hline Gender & -0.0041 & 0.507 & Willingness to participate in insurance & $0.0049^{* * *}$ & 0.071 \\
Age & 0.0003 & 0.259 & Crop insurance satisfaction & $0.0226^{* *}$ & 0.000 \\
Educational level & $0.0052^{* * *}$ & 0.000 & Regional economic development level & \\
Total family size & $-0.0061^{* *}$ & 0.012 & Regional per capita GDP & $0.0164^{* *}$ & 0.001 \\
\hline $\mathrm{R}^{2}$ & 0.4672 & F statistics & 55.1200 \\
Adjusted $\mathrm{R}^{2}$ & 0.4587 & The $P$-value corresponding to the F statistic & 0.0000 \\
\hline
\end{tabular}

${ }^{1}$ Single, double, and triple asterisks (*,**,***) indicate (statistical) significance at the $10 \%, 5 \%$, and $1 \%$ level, respectively. 
In the variables reflecting the basic characteristics of the family, the educational level of the head of household had a significant positive effect on changes of farmers' welfare, and a significance test was passed at the statistical level of 1\%. Less-educated families' labor skills and ability to accept new methods and resist risks were not conducive to the optimization and expansion of agricultural production. They also had relatively low non-agricultural employment opportunities and limited room for income growth. Previous studies have shown that education can promote farmers' independence from land, leading other welfare levels to increase with access to education. Improvements in educational access can improve other functions in addition to families' land resources. Programs to promote education can improve the welfare of farmers ( $\mathrm{Li}$ and Hongwu, 2012). The total household size had a significant negative impact on changes of farmers' welfare. The likely reason is that the total household size was too large, leading to two conclusions. One is that the larger the household population, the more labor will be available to improve family welfare. The other is that the larger the family size, the greater the number of dependents within the household. Our sample data may be more inclined to the second category. That is to say, households with a large number of dependents will inevitably experience a greater burden on the family, and the ability of farmers to adapt to the new environment can also be weakened and their welfare levels become harder to improve. In addition, the gender of the head of the household had a negative effect on the change in family welfare. That is, the level of the welfare of the household headed by the male was higher than that of a family headed by the female. The age of the head of the household and the family welfare are positively correlated, but neither of these indicators passed the significance test, so no further analysis was done here.

The impact of crop insurance policy variables on the changes to farmer household welfare is positive. The correlation coefficient between the two is positive and relatively large. In other words, farmers' participation in crop insurance can effectively raise the level of welfare, demonstrating the role of crop insurance in promoting farmers' family welfare. Changes in the welfare before and after participating in crop insurance are significantly affected by farmers' willingness to participate and their satisfaction with crop insurance, thus revealing their importance in terms of the ability of insurance to improve welfare. The implementation of crop insurance policies has a direct bearing on changes in farmers' welfare. Crop insurance effectively eliminates farmers' concerns and makes them more confident in future agricultural production, thus affecting farmers' emotional wellbeing, farmland quality, farmland area, agricultural income, and household consumption. Understanding the willingness and satisfaction of farmers to invest in crop insurance would be conducive to the formulation, implementation, and improvement of crop insurance policies.

The regression results of the level of regional economic development on the changes in the welfare of farmers indicate that the higher the level of economic development, the easier it is to improve farmers' welfare. Farmers in areas with high economic development are more likely to improve their level of welfare after participating in crop insurance. The assessment of changes in farmers' welfare shows that Baotou City with higher economic development in the five sample areas, experienced the greatest increase in farmers' welfare, with an overall increase of 0.078, which was greater than the farmers in Bayannur with lower economic development level, which demonstrated an increase of just 0.018 . A possible explanation could be that due to the high level of economic development, the corresponding agricultural infrastructure and related supporting facilities in the region are already relatively complete. Local governments have invested more heavily in public services such as education, medical care, and social security, leading farmers to enjoy the benefits of these public facilities. The public service level may also be higher, which would help improve the farmers' own comprehensive quality and vision, making it easier to master advanced agricultural science and technology and to enhance production. At the same time, due to the higher level of economic development, farmers would have more opportunities for non-agricultural employment, allowing for greater opportunities for farmers to improve their welfare. The results of this study show that the level of regional economic development has, to a certain extent, played a role in promoting the transformation of farmers' welfare within their village. 


\section{Conclusions}

Sen affirmed and advocated the subjective status of human development. He was consumed with a concern for human beings. He believed that humans should be not only physical beings but also people who can make choices and take actions. Every good choice and correct action should be conducive to enhancing their voice and subjectivity, with the ultimate goal of improving their welfare. After participating in crop insurance, although the level of welfare of farmers rose under different conversion factors, it also declined in other areas. The evaluation results of welfare status demonstrate changes before and after participating in crop insurance in Inner Mongolia, with the overall welfare level of farmers increasing after participation in crop insurance, but the extent to which welfare improved was limited. The fuzzy evaluation index increased from 0.466 to 0.500 and reached a fuzzy state in which welfare was neither good nor bad. The protective effect and improvement of psychological experience caused by the supportive role of crop insurance were the most important factors in the improvement of farmers' welfare. The protective security function increased from 0.492 before participation to 0.608 . The psychological experience indicator increased from 0.500 before participation to 0.747 . However, farmers' family welfare was at an intermediate range of 0.4 to 0.5 both before and after the insurance participation. It also demonstrated that it still takes a greater level of work intensity to improve the welfare of the farmers. From the perspective of functional indicators, households participating in crop insurance had a high family economic status, environment, and leisure weight (in which the household economy has a weight of 0.986 , environmental weight is 0.726 , and leisure weight is 0.722 ), indicating that these three indicators have a great influence on the total welfare of farmers. The degree of subordination of family economic welfare increased, rising from 0.355 before participating in insurance to 0.373 , which is still at a relatively poor level. In addition, compared with the pre-insured period, the environmental and leisure welfare subordination levels declined, falling below the ambiguity of level 0.500 , and the welfare level are not very high. From the aspect of conversion factors, the education level of the head of household, the total household size, the crop insurance policy, and the level of regional economic development are the four most important factors that affect the degree of change in household welfare.

Based on the above conclusions, this paper believes that in order to boost the welfare level of farmers, we must increase their income while also considering the non-economic welfare of farmers through expansion of farmers' cultivation area, protection of the environment, reduction in air and noise pollution, and strengthening of community greening and development efforts. Also, to lift the welfare level of farmers, there should be protection of the natural landscape of rural areas, improving the living conditions and working environment of farmers, and improving farmers' satisfaction with public services. In general, in order to give full play to the role of crop insurance and further improve the welfare level of farmers, the government should also consider the following points:

First, local governments should increase their investment in education and training for ordinary farmers. In addition to raising academic qualifications, targeted vocational skills training for farmers will also be offered to improve their entrepreneurial skills and ability to obtain non-agricultural employment opportunities, and these will be continuously improved as a long-term mechanism. Second, in order to effectively reduce the pressure of family support, the government must review social security measures, increase funding for pensions and medical care, explore pensions and medical insurance suitable for rural residents, and further improve the social welfare of farmers, especially in economically underdeveloped areas. Third, at the same time, it must further improve the laws and regulations of policy-based crop insurance, rationally set insurance lines, and increase government support and subsidies. In particular, it should increase the proportion of subsidies to major grain-producing areas in the central and western provinces and gradually establish policy-based agricultural reinsurance. The purpose of the mechanism is to expand the level of protection and increase coverage, which is of great significance to improving the income of farmers and their welfare. Fourth, the government should increase the supervision for the operation of crop insurance, make the behavior of all subjects more standardized and strictly supervise the behavior of policyholders and insurers, so that China's crop insurance market will develop steadily and truly play a guarantee role. 


\section{Acknowledgements}

The authors are grateful to 2016 Inner Mongolia Natural Science Foundation Project (2016MS0703) for the support that made this research possible.

\section{References}

Babcock, B.A. 2011. Time to revisit crop insurance premium subsidies? Policy briefs, Center for agricultural and rural development, Iowa State University, Ames, IA, USA.

Carter, M.R., L. Cheng and A. Sarris. 2016. Where and how index insurance can boost the adoption of improved agricultural technologies. Journal of Development Economics 118: 59-71.

Cheli, B. and A. Lemmi. 1995. A totally fuzzy and relative approach to the multidimensional analysis of poverty. Economic Notes 24: 115-133.

Chen, X. 2004. Resource allocation and rural development in China. China Rural Economy 1: 4-9.

Cole, S., X. Gine, J. Tobacman, P. Topalova, R. Townsend and J. Vickery. 2013. Barriers to household risk management: evidence from India. American Economic Journal: Applied Economics 5: 104-135.

Duncan, J. and R.J. Myers. 2000. Crop insurance under catastrophic risk. American Journal of Agricultural Economics 82: 842-845.

Enjolras, G., F. Capitanio and F. Adinolfi. 2012. The demand for crop insurance: combined approaches for France and Italy. Agricultural Economics Review 13: 5-15.

Feng, W. 2004. China's agricultural insurance market failure and system supply. Financial Research 4: 124-129.

Goodwin, B.K. and V.H. Smith. 2012. The economics of crop insurance and disaster aid. AEI Press, Washington, DC, USA.

Goodwin, B.K., M.L. Vandeveer and J.L. Deal. 2004. An empirical analysis of acreage effects of participation in the federal crop insurance program. American Journal of Agricultural Economics 86: 1058-1077.

Gao, J., R. Qiao and A. Zhang. 2007. Fuzzy evaluation of farmers' welfare changes before and after farmland circulation based on Sen's available capabilities theory. Managerial World 6: 62-73.

Ghazanfar, S., Z. Qiwen, M. Abdullah, Z. Ahmad and M. Lateef. 2015. Farmers' perception and awareness and factors affecting awareness of farmers regarding crop insurance as a risk coping mechanism evidence from Pakistan. Journal of Northeast Agricultural University 22: 76-82.

Hou, L., Y. Mu and Y. Zeng. 2010. Empirical analysis of crop insurance subsidy policy and its impact on farmers' insurance purchase. Journal of Agricultural Economics 4: 19-25.

Huang, Y. 2015. Performance evaluation of crop insurance premium subsidy in China based on DEA empirical analysis of provincial panel pata from 2009 to 2013. Southwest Finance 5: 32-35.

Hueth, D.L. and W.H. Furtan. 1994. Economics of agricultural crop insurance: theory and evidence. Kluwer Academic Publisher, Boston, MA, USA.

Jia, H. and S. Wang. 2014. Analysis of farmers' welfare changes before and after concentration of residence and its influencing factors based on the survey of farmers in Jiangsu Province. China Rural Observation 1: 26-39.

Li, J. and T. Hongwu. 2012. Analysis of welfare status of farm households in Zhouzhi county, Shanxi Province based on available capabilities. Management Review 5: 66-72.

Li, J. 1996. The nature of agricultural insurance, legislative principles and development ideas. China's Rural Economy 1: 55-59.

Liang, P., Liang P. and Y. Dong. 2008. Empirical study on the impact of China's agricultural insurance on farmers' income. Management Modernization 1: 46-48.

Liu, Y., H. Hao and W. Ma. 2016. Research on the influence mechanism of government supporting agriculture policies on agricultural insurance demand. Journal of Agricultural Economics 10: 31-40.

Martinetti, E.C. 2000. A multidimensional assessment of well-being based on Sen's functioning approach. Rivista Internazionale Di Scienze Sociali 108: 207-239.

Mishra, P. 1996. Agricultural risk, insurance and income: a study of the impact and design of India's comprehensive crop insurance scheme. Avebury Publishing, Aldershot, UK. 
Nie, R., Y. Yan and X. Wang. 2013. Research on policy-based crop insurance welfare performance based on the evidence of Liaoning province microcosmic data. Agricultural Technology \& Economy 4: 69-76.

Qiu, B. and L. Zheng. 2016. Research on china's policy agricultural insurance efficiency from the perspective of catastrophe risk. Problems of Agricultural Economy 5: 69-76.

Sen, A. 1992. Inequality reexamined. Harvard University Press, Cambridge, MA, USA.

Sen, A. 1993. Capability and well-being. In: M. Nussbaum and A.K. Sen (eds.). The quality of life. Clarendon Press, Oxford, UK, pp. 30-53.

Torkamani, J. 2009. Effects of agricultural crop insurance on farmers' risk aversion and income distribution: a case study of fars province. Journal of Agricultural Economics Research 1: 34-47.

Wright, B.D. and J.A. Hewitt. 1990. All risk crop insurance: lessons from theory and experience. California Agricultural Experiment Station. Giannini Foundation, Berkeley, CA, USA.

Xu, M., X. Li and M. Wang. 2016. The government position of the domestic agricultural insurance market: the night watchman or the leader. Rural Economy 3: 78-82.

Xia,Y., Q. Sun and X. Sheng. 2015. Correcting the agricultural insurance market with financial subsidies. Economic Review 5: 75-78.

Zhang, F., K. Liu and S. Bai. 2013. Game analysis of farmers' moral risk in policy agricultural insurance. Journal of Northwest A\&F University (Social Science Edition) 4: 82-87.

Zhang Y. and H. Shi. 2007. Subsidy, welfare and policy-based crop insurance: an in-depth study based on welfare economics. Journal of Zhejiang University (Humanities and Social Sciences) 6: 138-146.

Zhang, Y., Q. Shi and H. Gu. 2006.The impact of crop insurance on the welfare of farmers and the state and an empirical study. Research in Institutional Economics 2: 1-23.

Zhao, Y. and Z. Chai. 2012. Farmers' evaluation of the effect of crop insurance indemnity based on a questionnaire of more than 500 households in Inner Mongolia. China Rural Economy 4: 66-75. 
